\title{
UK experience in neonatal extracorporeal membrane oxygenation
}

\author{
G A Pearson, D J Field, R K Firmin, A S Sosnowski
}

\begin{abstract}
Extracorporeal membrane oxygenation (ECMO) is a life support technique capable of supporting pulmonary, cardiac, or cardiopulmonary function. It has proved most successful in neonatal respiratory failure. We report the initial UK experience with a survival rate of $80 \%$ in 15 neonates (gestations 36-41 weeks, birth weights 2690-3990 g) whose condition exceeded American criteria for ECMO treatment for a prolonged period before referral. Ages at referral varied from 11 to 240 hours and the duration of bypass required varied from 30 to 240 hours respectively.
\end{abstract}

Extracorporeal membrane oxygenation (ECMO) is a life support technique that has evolved from refinements in heart-lung bypass technology. It is capable of supporting pulmonary, cardiac, or cardiopulmonary failure, sustaining life for days or weeks. It has proved to be most successful in neonatal respiratory failure. The initial experience in the USA by Bartlett et al was in $1975 .^{1}$ Published results on 45 newborn cases with a survival rate of $55 \%$ followed in $1982 .{ }^{2}$ Further improved results from this and other centres rapidly followed. ${ }^{3}$ Since 1985 the treatment has been considered standard for mature infants with severe respiratory failure in the USA and survival rates exceed $90 \%$ in some centres. ${ }^{4}$ There are 80 centres worldwide and nearly 6000 neonates have received pulmonary support. ${ }^{5} \mathrm{We}$ report the initial UK experience of neonatal ECMO.

\section{Patient selection and methods}

At the Heartlink ECMO Centre (Leicester) the ECMO service started in 1989. So far a total of 28 patients have been treated; of these, 15 were neonates. Patient selection followed American guidelines. ${ }^{6}$ Under these guidelines patients less than 34 weeks' gestation or less than $2000 \mathrm{~g}$, infants with intraventricular haemorrhage, and infants that had received ventilation for more than 10 days are contraindicated. Infants with chromosomal abnormalities were considered ineligible for treatment. Patients who did not have any exclusion criteria and who had failed to respond to maximal conventional medical treatment were considered for ECMO. In America the most common indicators of failing conventional medical treatment are numerical indices such as alveolar arterial oxygen difference or, more commonly, oxygenation index is calculated according to the formula

$$
\frac{\text { Mean airway pressure } \times \mathrm{FIO}_{2}(\%)}{\text { Postductal } \mathrm{Po}_{2}(\mathrm{~mm} \mathrm{Hg})}
$$

and if it exceeds 40 in three measurements taken at intervals of 30 minutes, ECMO is indicated. $\left(\mathrm{FIO}_{2}\right.$ is fractional inspiratory oxygen and $\mathrm{PO}_{2}$ is oxygen tension.)

All patients received cardiac and cranial ultrasound before establishing the bypass in an attempt to exclude cyanotic heart disease and intraventricular haemorrhage respectively.

The patients referred came from centres throughout the UK and one patient was referred from Germany. Any appropriate referral was accepted if space was available. The selection criteria produced a population whose gestations were in the range 36-41 weeks and birth weights 2690-3990 (mean $3390 \mathrm{~g}$ ).

The ECMO team is multidisciplinary and includes neonatologists, paediatric cardiologists, cardiothoracic surgeons, perfusionists, and 'extended role' nurses. Circuit design is shown in the figure. Cannulation was by surgical cutdown. The cannulae used were chosen according to the size of the patient and the type of extracorporeal life support required. Single lumen 8-14 French gauge Biomedicus or Elicath and 14 French gauge double lumen Kendall cannulae were used. Venovenous (V-V) and venoarterial (V-A) extracorporeal life support were both used. The circuits were constructed from $\frac{1}{4} "$ $(0.63 \mathrm{~cm})$ Supertygon tubing and venous drainage was to Scimed silicon venous bladders. The bladder that was used is distensible and sits within a tripswitch, so that if venous drainage is inadequate, the collapse of the bladder inhibits pump flow. Blood was drawn from the bladders by Stockert roller pumps with Supertygon raceways. The oxygenators were Scimed 0600 or 0800 silicon membrane oxygenators capable of oxygenating up to blood flows far greater than those necessary for full cardiopulmonary support in a neonate. In the oxygenator the blood phase is separated from the gas phase by a spiralled Silastic membrane (Dow Corning). The flow of gas (or 'sweep') moves in countercurrent direction to blood flow to maximise diffusion gradients between the two phases.

Full pulmonary support requires blood flow rates in $100 \mathrm{ml} / \mathrm{kg} / \mathrm{min}$ in $\mathrm{V}-\mathrm{A}$ perfusion and 


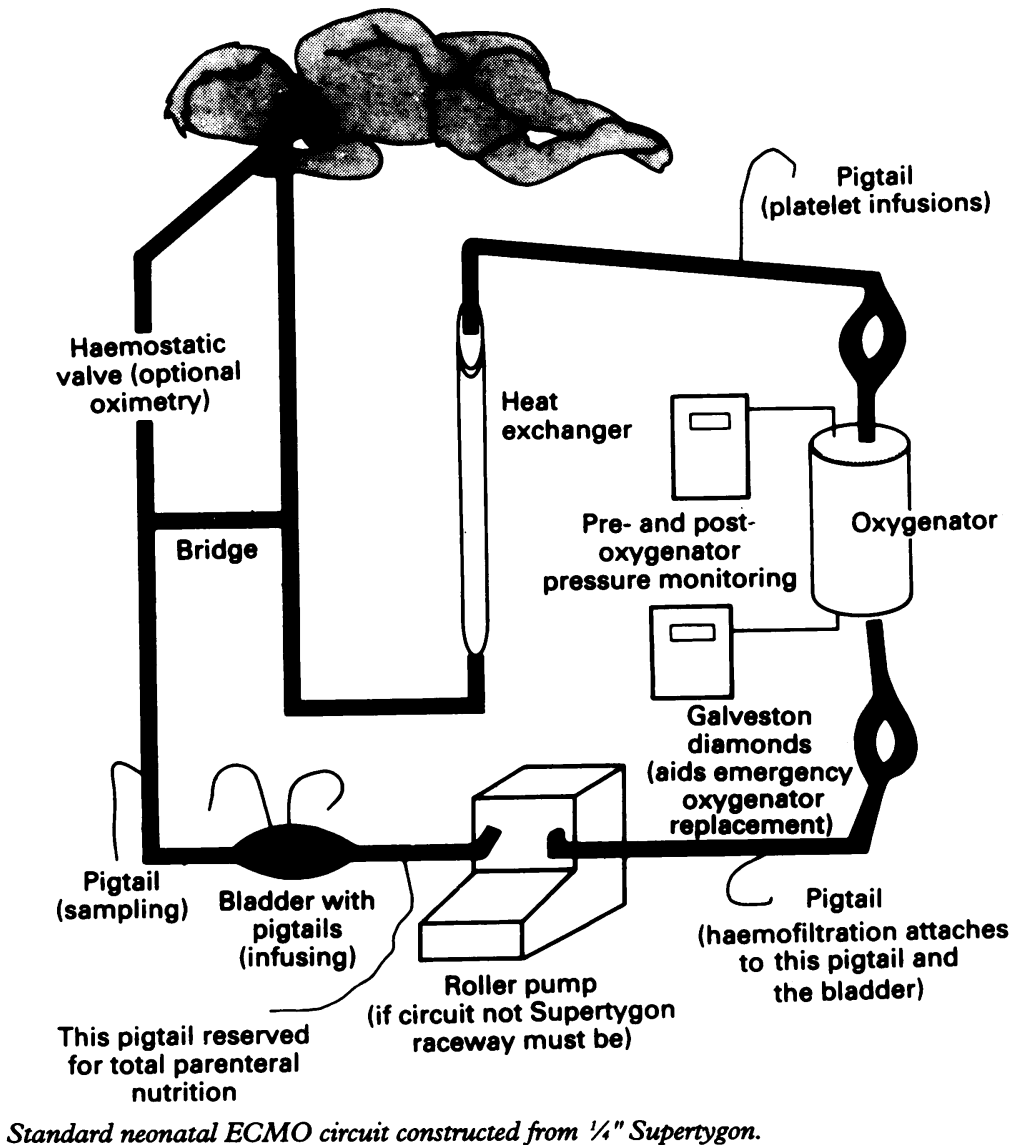

$120 \mathrm{ml} / \mathrm{kg} / \mathrm{min}$ in $\mathrm{V}-\mathrm{V}$ perfusion. Sweep gas composition was kept constant as $100 \%$ oxygen, and patient oxygenation was adjusted as a function of blood flow across the oxygenator. Under these circumstances the diffusion gradient for carbon dioxide is high and carbon dioxide clearance is mainly a function of the rate of gas flow across the membrane-the 'sweep rate'.

The heat exchangers employed were 'Cincinatti subzero' with disposable Scimed 'Ecmotherm' water columns. Patients were kept lightly sedated by an opiate infusion or by the addition of isoflurane to the sweep gas (R K Firmin et al, presented at European Extracorporeal Life Support Association, Paris 1991). Platelet consumption by the circuit was balanced by transfusion to keep the platelet count above $120 \times 109 / 1$ with an

Table 1 UK neonatal ECMO

\begin{tabular}{llllll}
\hline Case No & Diagnosis & $\begin{array}{l}\text { Age at } \\
\text { referral } \\
\text { (hours) }\end{array}$ & $\begin{array}{l}\text { Mode of } \\
\text { cannulation }\end{array}$ & $\begin{array}{l}\text { Duration } \\
\text { of bypass } \\
\text { (hours) }\end{array}$ & Outcome \\
\hline 1 & PFC & 240 & V-A & 130 & Died \\
2 & PFC & 16 & V-V & 120 & Died \\
3 & MAS & 24 & V-V & 57 & Survived \\
4 & RDS & 60 & V-V & 115 & Died \\
5 & RDS & 44 & V-V & 43 & Survived \\
6 & MAS & 11 & V-V & 100 & Survived \\
7 & MAS & 44 & V-A & 71 & Survived \\
8 & MAS & 12 & V-A & 545 & Survived \\
9 & TAPVC & 119 & V-A & 91 & Survived \\
10 & PFC & 86 & V-A & 222 & Survived \\
11 & CDH & 102 & V-A & 202 & Survived \\
12 & PFC & 18 & V-V & 36 & Survived \\
13 & RDS & 180 & V-A & 240 & Survived \\
14 & PFC & 21 & V-A & 59 & Survived \\
15 & PFC & 54 & V-A & 125 & Survived \\
\hline
\end{tabular}

PFC=persistent fetal circulation, MAS=meconium aspiration syndrome, $R D S=$ respiratory distress syndrome, TAPVC=total anomalous pulmonary venous connection, $\mathrm{CDH}=$ congenital distress syndrome, TAPragmatic hernia. optimum of $180 \times 109 /$. Anticoagulation was achieved with ah heparin bolus of 40 units $/ \mathrm{kg}$ followed by an infusion of 20-60 units/ $\mathrm{kg} /$ hour monitored by activated whole blood clotting time and thrombin time. The degree of anticoagulation used was enough to prolong the whole blood clotting time to 180-200 seconds (much less than that used in conventional heart-lung bypass). Daily cranial and cardiac ultrasound examinations formed part of the clinical monitoring.

\section{Results}

All the reported cases where referred for pulmonary support, conventional medical treatment having been judged by the referring centres to be failing. In most cases ECMO was considered a last resort. Twelve of the 15 patients survived $(80 \%)$. The results and individual diagnoses of these patients are shown in table 1 .

Table 2 summaries the illness severity of the patients referred. In our referral group, the ventilator settings by the time of referral averaged rate 65 (range 40-100) peak inspiratory pressure 43 (range $30-55$ ) $\mathrm{cm}$ $\mathrm{H}_{2} \mathrm{O}$, positive end expiratory pressure 5 (range 4-8) $\mathrm{cm} \mathrm{H}_{2} \mathrm{O}$. All were receiving $100 \%$ oxygen. The patients were receiving up to four inotropes in a variety of doses and between one and three different pulmonary vasodilators. By the time of presentation, despite this support, two patients were in a state of cardiac arrest secondary to hypoxia at the point of cannulation, both of whom survived. One patient died after referral but before ECMO.

No mechanical complications were experienced. Haemolysis was not observed in any patient. One patient had uncontrolled haemorrhage from a chest drain inserted into the lung before ECMO; a 10 day perfusion was still possible and the patient survived. One patient had subglottic oedema secondary to intubation which delayed extubation after ECMO. One patient referred at 6 days of age was left with mild bronchopulmonary dysplasia. Four patients required a total of five operations while on ECMO. These included surgical repair of total anomalous pulmonary venous connection (TAPVC), ligation of patent ductus arteriosus, and thoracotomy for haemothorax. Seizures observed in two patients before ECMO, recurred during ECMO in one case and presumably reflected an earlier hypoxic injury. One patient had a first seizure during ECMO of similar aetiology. Pre-ECMO cranial ultrasound examinations were abnormal in three patients all of whom had demonstrable periventricular flare. In all cases these appearances resolved after two days of perfusion. One patient with a normal pre-ECMO cranial ultrasound died after a catastrophic intraventricular haemorrhage.

Of the three patients that died, one had an intraventricular haemorrhage; one an irreversible pulmonary disease; and one an ischaemic gut injury, before establishing ECMO, that evolved during bypass. Much of 
Table 2 UK neonatal ECMO condition at cannulation

\begin{tabular}{|c|c|c|c|c|c|c|c|c|c|}
\hline \multirow[t]{2}{*}{ Case No } & \multirow{2}{*}{$\begin{array}{l}\text { Ventilator } \\
\text { pressure } \\
\left(\mathrm{cm} \mathrm{H}_{2} \mathrm{O}\right)\end{array}$} & \multicolumn{3}{|c|}{$\begin{array}{l}\text { Postductal gases } \\
(\mathrm{kPa})\end{array}$} & \multicolumn{5}{|c|}{ Conventional treatment had included: } \\
\hline & & $\frac{(k P a)}{p H^{*}}$ & $\mathrm{PCO}_{2}{ }^{*}$ & $\mathrm{PO}_{2}^{*}$ & $\begin{array}{l}\text { Hign mean } \\
\text { airway pressure }\end{array}$ & $\begin{array}{l}\text { High rate } \\
(>60 / \text { min) }\end{array}$ & Paralysis & $\begin{array}{l}\text { Pulmonmary } \\
\text { vasodilators }\end{array}$ & Inotropes \\
\hline $\begin{array}{r}1 \\
2 \\
3 \\
4 \\
5 \\
6 \\
7 \\
8 \\
9 \\
10 \\
11 \\
12 \\
13 \\
14 \\
15\end{array}$ & $\begin{array}{l}38 / 3 \\
44 / 4 \\
36 / 4 \\
45 / 4 \\
30 / 5 \\
40 / 5 \\
36 / 5 \\
46 / 4 \\
54 / 8 \\
50 / 4 \\
42 / 4 \\
45 / 5 \\
60 / 10 \\
36 / 4 \\
35 / 5\end{array}$ & $\begin{array}{l}7 \cdot 35 \\
6 \cdot 7 \\
6 \cdot 7 \\
7 \cdot 2 \\
7 \cdot 29 \\
6 \cdot 9 \\
7 \cdot 49 \\
7 \cdot 48 \\
7 \cdot 65 \\
7 \cdot 51 \\
7 \cdot 34 \\
7 \cdot 09 \\
7 \cdot 22 \\
7 \cdot 2 \\
7 \cdot 52\end{array}$ & $\begin{array}{c}5.78 \\
10.8 \\
15.6 \\
7.9 \\
6.2 \\
11.6 \\
3.06 \\
3.7 \\
2.8 \\
4.2 \\
5.8 \\
8.9 \\
9.4 \\
6.8 \\
3.5\end{array}$ & $\begin{array}{c}4.4 \\
2.5 \\
3.9 \\
2.3 \\
6.5 \\
5.4 \\
6.3 \\
5.3 \\
9.8 \\
6 \\
2.8 \\
10.4 \\
6.8 \\
2.4 \\
3.4\end{array}$ & $\begin{array}{l}+ \\
+ \\
+ \\
+ \\
+ \\
+ \\
+ \\
+ \\
+ \\
+ \\
+ \\
+ \\
+ \\
+ \\
+\end{array}$ & $\begin{array}{l}+ \\
+ \\
+ \\
+ \\
+ \\
+ \\
+ \\
+ \\
+ \\
+ \\
+ \\
+ \\
+ \\
+ \\
+\end{array}$ & $\begin{array}{l}+ \\
+ \\
+ \\
+ \\
+ \\
+ \\
+ \\
+ \\
+ \\
+ \\
+ \\
+ \\
+ \\
+ \\
+\end{array}$ & $\begin{array}{l}+ \\
+ \\
+ \\
+ \\
+ \\
+ \\
+ \\
+ \\
+ \\
+ \\
+ \\
+ \\
+ \\
+ \\
+\end{array}$ & $\begin{array}{l}+ \\
+ \\
+ \\
+ \\
+ \\
+ \\
+ \\
+ \\
+ \\
+ \\
+ \\
+ \\
+ \\
+ \\
+\end{array}$ \\
\hline
\end{tabular}

${ }^{*} \mathrm{FIO}_{2}$ at $100 \%$.

follow up data is at an early stage but is available on all 12 survivors. We are aware of two patents for whom there have been concern regarding development. Both received V-V support and therefore did not have carotid artery ligation. One was cannulated during cardiac arrest. The remaining 10 (age ranges 1-7 months) are reportedly developing normally.

\section{Discussion}

The numerical indices in common usage to define a treatment group for neonatal ECMO select a group whose survival with conventional treatment (from retrospective data) would be $20 \%$. All of the patients reported had disorders far exceeding American criteria for treatment for a prolonged time before their referral (up to 100 hours). The main criterion for referral in this country has been a failure to respond to maximal conventional medical treatment. What constitutes maximal medical treatment is something that is addressed individually in each referring unit and is not restricted to indices of oxygenation. Extracorporeal circulation can efficiently remove carbon dioxide as well as oxygenate in respiratory failure. ${ }^{7}$ The threshold for referral for ECMO seems to be falling and this has contributed to the fact that the last 11 consecutive cases have survived.

A very detailed database of all patients treated with ECMO worldwide is maintained by the participants at the Extracorporeal Life Support Organisation (ELSO) Data Registry in Ann Arbor, Michigan. Worldwide close to 6000 neonates have been treated with an overall survival of $83 \%$. The ELSO database survival figures by diagnosis are given in table 3. Babies with diaphragmatic hernia and babies with established parenchymal lung

Table 3 ELSO database results of neonatal ECMO

\begin{tabular}{lll}
\hline Primary diagnosis & $\begin{array}{l}\text { Total No } \\
\text { (cumulative) }\end{array}$ & $\begin{array}{l}\text { Survival } \\
\text { (\%) }\end{array}$ \\
\hline Meconium aspiration & 2067 & 93 \\
Congenital diaphragmatic hernia & 996 & 61 \\
Respiratory distress syndrome & 788 & 85 \\
Pneumonia/sepsis & 752 & 77 \\
Persistent fetal circulation & 692 & 88 \\
Air leak syndrome & 22 & 59 \\
Other & 162 & 81 \\
Total & 5479 & 83 \\
\hline
\end{tabular}

disease have the lowest survival rates. It must be remembered that persistent fetal circulation occurs as a secondary feature of most of the diagnoses listed. The referral pattern for treatment in the UK has not followed the worldwide trends (although the sample size is small). The most striking differences are the low incidence of referrals of patients with congenital diaphragmatic hernia and sepsis (this category includes pneumonia). It is unlikely that UK pattern of disease for congenital diaphragmatic hernia differs greatly from the American experience and as UK patient numbers increase the pattern may change. It has been suggested by Professor Bartlett that ECMO is required on average for five out of every thousand neonatal intensive care admissions ( $\mathrm{R} \mathrm{H}$ Bartlett, presented at UK National ECMO Conference, Leicester, 1991).

An $80 \%$ survival rate in this series is encouraging but not conclusive of the efficacy of ECMO. There have been two prospective trials of ECMO.$^{8}$ Neither used unbiased randomisation because of ethical considerations in the face of similar $80 \%$ survival rates. Results have therefore been difficult to interpret and not all authors believe the situation proved. ${ }^{10-12} \mathrm{~A}$ randomised controlled trial is necessary for unequivocal proof of ECMO's advantages over conventional treatment ${ }^{1013}$ and the opportunity for this trial should be taken in the UK.

Neurological morbidity in some series has not differed from conventional medical treatment of similarly sick patients. ${ }^{14}$ Our identified incidence of developmental delay is currently at most $13 \%$ of survivors. The degree of resultant handicap has yet to be established. Such data should be included in any future trial of ECMO. There is widespread (although not universal) feeling, which our data may support, that cannulation during cardiac arrest is associated with a high neurological morbidity and may be inadvisable.

If one accepts Bartlett's estimate of the number of patients likely to require ECMO, (R H Bartlett, presented at UK National ECMO Conference, Leicester, 1991), even at peak utilisation of ECMO in the UK most units would refer at infrequent intervals. There is therefore a limit to the number of units required by the UK. The transport of 
patients to an ECMO centre is associated with a mortality which should be taken into account. ${ }^{15}$ Transport while on ECMO is possible but early referral to a centre with ECMO facilities is preferable. Preparations for a formal randomised UK trial of ECMO continue. It is anticipated that randomisation will take place at the referring centre to enable transportation risks to be evaluated.

The facilities necessary at an ECMO centre require the juxtaposition of neonatal expertise with full paediatric cardiac surgical backup, including open cardiac surgery. It is inevitable that some patients with cyanotic congenital heart disease will be cannulated for ECMO before the diagnosis is made. In our series we cannulated one baby with TAPVC despite two echocardiograms. Each scan was performed by skilled echocardiographers but performed under unfavourable conditions (portable equipment for patients with very poor echo windows due to lung hyperinflation). American centres have had similar experiences with an incidence of approximately one in 90 cases. ${ }^{5}$ Transport for surgery while on ECMO support is different, even within an ECMO facility.

To initiate ECMO treatment costs on average $£ 1500$ per patient and our best all inclusive estimate of costs is $£ 850$ a day. This differs little from conventional treatment. We believe the financial advantage of this labour intensive alternative to conventional medical treatment may be that the duration of hospitalisation is significantly shortened. It is intended that during the prospective randomised trial of ECMO versus conventional treatment comparative costing will be formally investigated.

\section{Conclusion}

The survival rate of patients treated with ECMO in the UK appears to follow that in the USA. This is despite the fact that the neonates treated were in a far more critical condition, as judged by the America criteria for treatment for up to 100 hours before referral. ECMO seems therefore to be a potent life support resource for the sickest neonates. Despite doubts in some quarters, ${ }^{11} 1216$ the UK neonatal population contains infants who may benefit. We feel it is essential to proceed to a randomised trial before the same ethical constraints that precluded such a trial in the USA apply here.
We gratefully acknowledge the support and sponsorship of Heartlink, the Cardiac Childrens' Charity, who made the introduction of ECMO to the UK possible, and the assistance of the Variety Club of Great Britan.

1 Bartlett RH, Gazzaniga AB, Jefferies $R$, et al. Extracorporeal membrane oxygenation (ECMO): cardiocorporeal membrane oxygenation (ECMO): cardiopulmonary support in infancy. American Society

2 Bartlett RH, Andrews AF, Toomasian JM, et al. Extracorporeal membrane oxygenation (ECMO) for neonatal respiratory failure: 45 cases. Surgery 1982;92: 425-33.

3 Toomasian JM, Snedcor SM, Cornell R, et al. National experience with extracorporeal membrane oxygenation for newborn respiratory failure: data from 715 cases. American Society for Artificial Internal Organs Transactions 1988;34:140-7.

4 Bartlett RH, Gazzaniga AB, Toomasian TM. Extracorporeal membrane oxygenation (ECMO) in neonatal respiratory failure: 100 cases. Ann Surg 1986; 204:236-45.

5 Extracorporeal Life Support Organisation. Data registry Ann Arbor, Michigan: ELSO, 1991.

6 Bartlett RH. Extracorporeal life support for cardiopulmonary failure. Curr Prob Surg 1990;27:621-705.

7 Gattinoni L, Presenti A, Mascheroni D. Low frequency positive pressure ventilation with extracorporeal $\mathrm{CO}_{2}$ positive pressure ventilation with extracorporeal $\mathrm{CO}_{2}$
removal in severe acute respiratory failure. $¥ A M A$

8 O'Rourke PP, Krone B, Vacanti J. Extracorporeal membrane oxygenation and conventional medical therapy in neonates with persistent pulmonary hypertension of the newborn: a randomised prospective study. Pedatrics 1989;84:957-63.

9 Bartlett RH, Roloff DW, Cornell RG. Extracorporeal circulation in neonatal respiratory failure: a randomised prospective study. Pediatrics 1985;76:479-87.

10 Elliot SJ. Neonatal extracorporeal membrane oxygenation: how not to assess novel technologies. Lancet 1991; 337:476-8.

11 Rose SJ. Extracorporeal membrane oxygenation. BMF 1990;301:609.

12 Greenough A, Emery E. ECMO and the outcome of mechanical ventilation in infants of birthweight over $2 \mathrm{~kg}$. mechanical ventilation

13 Sosnowski AW, Bonser SJ, Field DJ. Extracorporeal membrane oxygenation. BMf 1990;301:303-4.

14 Glass P, Miller M, Short B. Morbidity for survivors of extracorporeal membrane oxygenation: neurodevelopmental outcome at one year of age. Pediatrics 1989;83:72-8.

15 Brudno DS, Boedy RF, Kanto WPJ. Hidden mortality rate associated with extracorporeal membrane oxygenation. f Pediatr 1990;117:462-4.

16 Anonymous. Persistent foetal circulation and extracorporeal membrane oxygenation [Editorial]. Lancet 1988;ii:1289-91.

\section{Addendum}

Since this article was first submitted for publication the series of patients treated with ECMO in our centre has increased. The proportion of neonates among these patients has also increased (to 64\%). Data from 37 neonates (from a total of 58 patients) are now available. The expected fall in the threshold for referral has not occurred but a survival rate of $80 \%$ has been maintained. The incidence of developmental delay recognised in our survivors is currently $8 \%$. The UK prospective trial of neonatal ECMO against conventional medical treatment is due to start in September 1992. 